\title{
R4 Incorporação do alvo HBV no Kit NAT brasileiro produzido por Bio-Manguinhos
}

Patrícia Alvarez'1, Elisabete Andrade1, Daniele Rocha1, Marcela Fontana $^{1}$, Marisa Ribero ${ }^{1}$, Elaine Motta ${ }^{1}$, Antonio G. P. Ferreira ${ }^{2}$

1 Bio-Manguinhos, Fiocruz, Rio de Janeiro, RJ

2 PRED, VDTEC, Bio-Manguinhos, Fiocruz, Rio de Janeiro, RJ

Introdução: Atualmente, para triagem de doadores de sangue no Brasil, são realizados testes NAT para HIV e HCV. Visando ampliar ainda mais a segurança transfusional, o Kit NAT foi aperfeiçoado para detectar, adicionalmente, amostras com o vírus da Hepatite B (HBV). A partir da decisão estratégica, conseguimos, em curtíssimo espaço de tempo (6 meses), a definição dos alvos moleculares, padronização de insumos e modelo de apresentação, além das análises de desempenho, estando pronto para ser incorporado ao produto.

Objetivo: Estabelecer o ensaio de diagnóstico molecular para detecção do HBV na plataforma de PCR em Tempo Real, incorporando ao Kit NAT HIV/HCV de Bio-Manguinhos um segundo módulo de amplificação contendo os alvos para HBV/FAM e Partícula Calibradora/ Dye3. Este novo modelo, ampliado, deverá cumprir requisitos técnicos de desempenho, como sensibilidade de $50 \mathrm{Ul} / \mathrm{mL}$, entre outros.

Metodologia: Os iniciadores e sonda usados na padronização do ensaio estão na região S do HBV. Foram obtidas as provas de conceito e o alcance de todos os requisitos técnicos de desempenho, através do processamento de amostras clínicas verdadeiras positivas, amostras de painel internacional e de soro-conversão para HBV, definindo a sensibilidade do novo modelo de produto. Amostras verdadeiras negativas permitiram estabelecer níveis de especificidade. A padronização e testes foram realizados, individualmente e em "pool" de 6 amostras.

Resultados: O processamento do LOD de 8 replicatas de cada concentração de cerca de 20 amostras HBV verdadeira positivas, demostrou que o ensaio é capaz de detectar para todas estas amostras todas as replicatas de $10 \mathrm{Ul} / \mathrm{mL}$. O Módulo de Amplificação para HBV foi também capaz de detectar o painel de soro-conversão em "pool" e em "single". Além disso, a partir de amostras de painel internacional, obtivemos sensibilidade de $4,86 \mathrm{Ul} / \mathrm{mL}$ (Probit 95\%). Os testes de especificidade foram feitos com 300 amostras verdadeiras negativas e demostraram $100 \%$ de especificidade.

Conclusão: Todas as características técnicas de sensibilidade, especificidade e reprodutibilidade foram definidas em tempo recorde. O limite de sensibilidade de 4,86 UI/mL é extremamente satisfatório e está cerca de 10 vezes menor que o requisito de $50 \mathrm{UI} / \mathrm{mL}$ aceito 
internacionalmente. A prova de conceito deste novo Módulo de Amplificação foi obtida através da total detecção do painel de soroconversão HBV. A incorporação do alvo HBV no Kit NAT Brasileiro é uma realidade e está em fase de validação de lotes Piloto, visando à submissão de processo junto a ANVISA.

Palavras-Chave: NAT, HBV, Diagnóstico Molecular 